\title{
Yoğunluk ayarlı radyoterapi yapılan meme kanseri hastalarında, tiroid bezinde ikincil malignite gelişme riski tahmini
}

\author{
Songül Barlaz Us ${ }^{1}$, Aytül Kanat ${ }^{2}$, Yusuf Tolga Şanlı ${ }^{2}$ \\ ${ }^{1}$ Mersin Üniversitesi Tıp Fakültesi Radyasyon Onkolojisi Anabilim Dalı, Mersin \\ ²0nko Özel Onkoloji Merkezi, Mersin
}

$\ddot{0} \mathbf{z}$

Amaç: Meme radyoterapisinden (RT) sonra tiroid bezinde radyasyona bağlı ikincil malignite gelişme riski artmaktadır. Bu çalışmada yoğunluk ayarlı radyoterapi (Intensity modulated radiotherapy-IMRT) yapılan meme kanseri hastalarında tiroid bezi malignitesi gelișme riskinin değerlendirilmesi amaçlanmıștır. Yöntem: Çalıșmada total mastektomi ve meme koruyucu cerrahi sonrası IMRT uygulanan 70 meme hastası değerlendirilmiştir. Hastalarda tiroid bezinde ikincil malignite gelişme riski, ERR (Estimating relative risk-tahmini rölatif risk) modeli kullanılarak hesaplanmıștır. Bulgular: Supra klaviküler bölgenin, RT alanına dahil edildiği hastalarda (Grup-1), ERR değeri supraklaviküler bölgenin RT alanına dahil edilmediği hastalardan (Grup-2) daha yüksek olduğu görülmüştür. ERR değerleri, yaş arttıkça eksponansiyel olarak azalmıştır. Gruplar arasındaki tiroid bezi dozları farklı olmasına rağmen, yaş arttıkça iki gruptaki ERR değerleri birbirine yaklaşmıştır. Sonuç: Meme IMRT’si sonrası, tiroid bezinde ikincil malignite gelişme riski, genç hastalarda daha yüksektir. Bu nedenle genç hastalardaki RT uygulamalarında sağlam ve geçerli risk değerlendirmesi tavsiye edilmektedir.

Anahtar sözcükler: Meme IMRT, tiroid bezi, ikincil malignite riski

\section{Estimation of secondary malignancy development risks in thyroid gland on breast cancer patients treated with intensity modulated radiotherapy}

\begin{abstract}
Aim: The risk of developing secondary malignancy due to radiation in the thyroid gland can increase after breast radiotherapy (RT). In this study, it was aimed to evaluate the risk of developing thyroid gland malignancy in breast patients treated with intensity modulated radiotherapy (IMRT). Method: In this study, 70 breast cancer patients were received IMRT after total mastectomy and breast conserving surgery were analyzed. The risk of developing secondary malignancy in patients with thyroid gland was evaluated using the Estimating relative risk (ERR) model.
\end{abstract}

Yazının geliş tarihi: 13.04 .2018

Yazının kabul tarihi: 06.09.2018

Sorumlu Yazar: Songül Barlaz Us, Mersin Üniversitesi Tıp Fakültesi Radyasyon Onkolojisi Anabilim Dalı Çiftlikköy Kampüsü Yenişehir/Mersin

İş Tel: 0(324) 241 0000-22610, E-posta: barlaz@gmail.com 
Results: ERR values of Group-1, supraclavicular region included RT field were higher than Group-2, supraclavicular region was not included in the RT field. ERR values were decreased exponentially with the increasing age. Although the thyroid gland doses were different between the groups, as the age increased, the ERR values in the two groups were close to each other. Conclusion: The secondary malignancy risk of thyroid gland was higher in younger breast cancer patients. We suggest highly qualified risk analyzes at younger breast cancer patients who received IMRT.

Key words: Breast IMRT, thyroid gland, secondary malignancy risk

\section{Giriş}

Meme kanseri dünyada en sık görülen kanser türlerinden biridir. Son yıllarda sekiz kadından biri meme kanseri olmakta ve özellikle 40 yaş altındaki kadınlarda meme kanseri insidansının arttığı görülmektedir. ${ }^{1}$ Radyoterapi (RT) meme kanseri temel tedavi yöntemlerinden biridir. $^{2}$ Yoğunluk ayarlı radyoterapi (Intensity modulated radiotherapy-IMRT) tekniği, meme radyoterapisinde hedef hacme istenen dozu veren ve kritik organ risklerini (OaR) mümkün olduğunca azaltan bir ışınlama tekniğidir. ${ }^{3}$ IMRT gibi gelişmiş RT teknikleri ile kritik organ dozları mümkün olduğunca azaltılabilmesine rağmen, meme RT'si sonrası uzun dönem sağ kalımlarda tiroid bezi, karşı meme ve akciğerlerde radyasyona bağlı ikincil malignite gelişebilmektedir. ${ }^{4,5}$

Son zamanlarda ulusal ve uluslararası çalışma grupları düşük LET'li (Linear energy transfer-lineer enerji transferi) radyasyonların düşük seviyeli ıșınlamalarında tahmini kanser riski için modeller geliștirmișlerdir. ${ }^{6-8}$ Epidemiologistler, kanser tahmini risk hesaplamaları için iki farklı model tanımlamaktadırlar. Bunlar, ERR (Estimating relative risk- tahmini rölatif risk) ve EAR (Absolute relative risk-mutlak rölatif risk)'dir. Modeller, cinsiyet, ışınlama yaşı, doz hızı ve diğer faktörler dikkate alınarak kanser insidansının ve ölüm oranlarının yaşam boyu risklerinin tahmin edilmesi için geliştirilmiştir. Risk tahminlerinde, tüm solid kanserler için istatistiksel değerler kullanılmaktadır.

Radyasyon ışınlaması ve ikincil maligniteler arasındaki ilişkilerde risk tahmini için hem ERR hem de EAR modelleri kullanılabilir. ERR, radyasyon almamış popülasyon ile radyasyon almış popülasyon arasındaki tahmini risktir, birimsizdir, matematiksel ve istatistiksel açıdan avantajlıdır ve küçük riskler için anlaşılması kolaydır. EAR ise mutlak popülasyondaki risk oranının tahmini ile yakından ilişkilidir ve tüm popülasyona bağlıdır. Birimi 10.000 kişi-yll'dir. Popülasyondaki tüm faktörlerin hesaba katılması zor olduğu için risk değerlendirmesinde ERR modeli, EAR modeline göre daha avantajlıdır.7,9

$\mathrm{Bu}$ çalışmada, IMRT uygulanan 70 meme hastasında tiroid bezinde ikincil malignite gelişme riski, ERR modeli kullanılarak değerlendirilmiştir.

\section{Yöntem}

\section{Hasta Grupları ve Tedavi Planlaması}

Klinik Çalışma öncesi, Mersin Üniversitesi bașvurularak 25/01/2018 tarihli ve 2018/36 sayılı etik kurul onayı alınmıştır. Çalışmada, primer meme kanseri tanısı konmuş, total mastektomi ve meme koruyucu cerrahi sonrası, özel bir onkoloji merkezinde lineer hızlandırıcı tedavi cihazında RT uygulanmak üzere IMRT tedavi planlaması yapılmış, 29-80 yaş aralığında, kayıtlarına ulaşılabilen 70 kadın hasta değerlendirilmiștir. RT uygulanan 70 hastanın, 35'inin aksiller lenf tutulumu (Grup-1) vardır ve tedavi alanına supraklaviküler bölge dahil edilmiştir. 35 hastada ise aksiller lenf tutulumu yoktur (Grup-2) ve supraklaviküler bölge tedavi alanına dahil edilmemiştir. Supraklaviküler bölgesi RT alanına dahil edilen hastalarda tiroid bezi dozunun, supraklaviküler bölgesi RT alanına dahil edilmeyen hastalara göre daha yüksek olması beklenmektedir. $\mathrm{Bu}$ 
nedenle hastalar Grup-1 ve Grup-2 olarak sinıflandırılmıştır.

RT hazırlık aşamasında, hastalar standart meme sabitleme (immobolizasyon) sistemi kullanılarak pozisyonlandırılmıştır. Tedavi planında kullanılmak üzere memenin inferior, superior ve lateral sinırları ve kritik organları (karşı meme, akciğerler, kalp, tiroit) kapsayacak şekilde bilgisayarlı tomografi (BT) simülatör cihazı (SiemensSomatom Spirit) ile $5 \mathrm{~mm}$ aralıklarla BT kesitleri elde edilmiştir. Elde edilen bu kesitler, konturlama sistemine (SiemensDozimetrist) aktarlarak planlanan target hacim (PTV- Planning Target Volume) ve kritik organlar (Organ at Risk-Oar) (akciğerler, kalp, karşı meme, tiroid bezi) aynı hekim tarafından çizilmiştir. Daha sonra her bir hasta için elde edilen BT görüntüleri üzerinden, tanjansiyel alanlarda field-in-field IMRT tekniği kullanılarak PTV'ye günlük 2 Gy'den toplamda 50 Gy radyasyon dozu verilecek şekilde tedavi planlamaları (Linatech- Topslane) yapılmıştır. Şekil 1.'de tedavi planlamasına bir örnek görülmektedir.

Verilerin kaydedilmesi ve ERR (Estimated Relative Risk-Tahmini rölatif risk) hesabl

Radyoterapi verilmek üzere tedavi planlaması yapılan 70 hastanın, yaş, PTV, ortalama tiroid bezi dozu ve tiroid bezi hacmi kaydedilmiştir. $\mathrm{Bu}$ veriler kullanılarak, her bir hastanın tiroid bezi için ERR/Gy (1 Gy bașına tahmini rölatif risk) değerleri hesaplanmıștır. ERR/Gy hesaplamalarında aşağıdaki denklem kullanılmıştır7:

Erkekler için;

$$
\frac{E R R}{G y}=0.53 * \exp [-0.083 *(e-30)]
$$

Kadınlar için;

$$
\frac{E R R}{G y}=1.05 * \exp [-0.083 *(e-30)]
$$

Denklemdeki “ $e$ ", ışınlamanın yani RT’nin uygulandığı yaşı ifade etmektedir.
Denklemdeki kadınlar için olan ifade kullanılarak elde edilen ERR/Gy değeri, tiroidin aldığı ortalama doz ile çarpılarak ERR hesaplanmıştır. Büyük hacimli organlarda, ERR hesaplamalarında dozhacim histogramı (DVH) üzerinde her bir doz aralığı için hesaplama yapılması gerekmektedir. Fakat tiroid bezi gibi küçük hacimli organlarda ortalama tiroid bezi dozu kullanılabilmektedir. ${ }^{10}$ Şekil 2. 'de DVH'e bir örnek verilmiştir ve koyu mavi ile gösterilen eğri tiroid bezine aittir.

\section{İstatistiksel Analiz}

Grup-1 ve Grup-2 hastaları için elde edilen ERR değerlerinin yaşa bağlı değişimlerini daha homojen bir yaş aralığında ayrıntılı inceleyebilmek için her bir grup, 10'ar yaş aralıklı alt gruplara ayrilmıștır (29- 40, 41- 50, 51- 60, 61- 70, 71- 80 yaş aralıkları). Tahmini rölatif risk (ERR) ile hesaplanan her bir alt gruba, Univariate istatistiksel testi uygulanmış ve Grup-1 ile Grup-2 ve alt gruplar arasındaki korelasyon belirlenmiştir. Ayrıca Grup-1 ve Grup-2 için belirlenen her bir alt grubun standart sapmaları hesaplanmış, bar ve hata çubuğu (error bar) grafikleri çizdirilmiştir.

\section{Bulgular}

Grup-1 ve Grup-2 hastalarının ortalama tiroid bezi dozu, ortalama PTV dozu, tiroid bezi hacmi ve yaşları Tablo 1.'de görülmektedir. Görüldüğü gibi Grup-1 ve Grup-2 hastalarının ortalama PTV dozları, standart sapmaları ve tiroid bezi hacimleri birbirine yakındır. Fakat Grup-1 hastalarının tiroid bezi dozları beklenildiği üzere Grup-2 hastalarının dozlarına göre daha yüksektir. Grup-1 hastaları için ortalama tiroid bezi dozu 19.320 Gy iken, bu değer Grup-2 hastaları için 0.315 Gy'dir. 


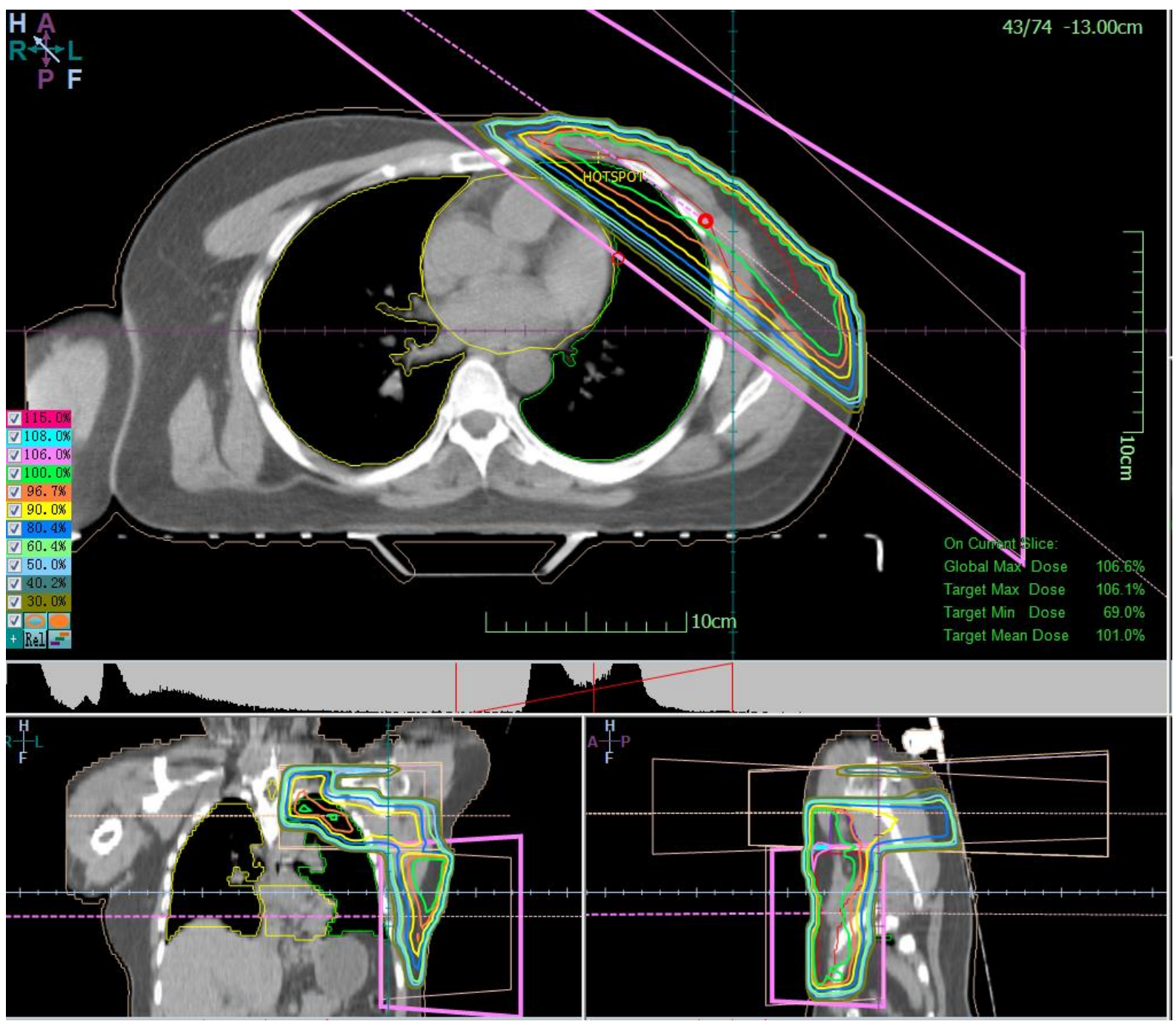

Şekil 1. Tedavi planlamasının 3 boyutlu doz dağılımına örnek

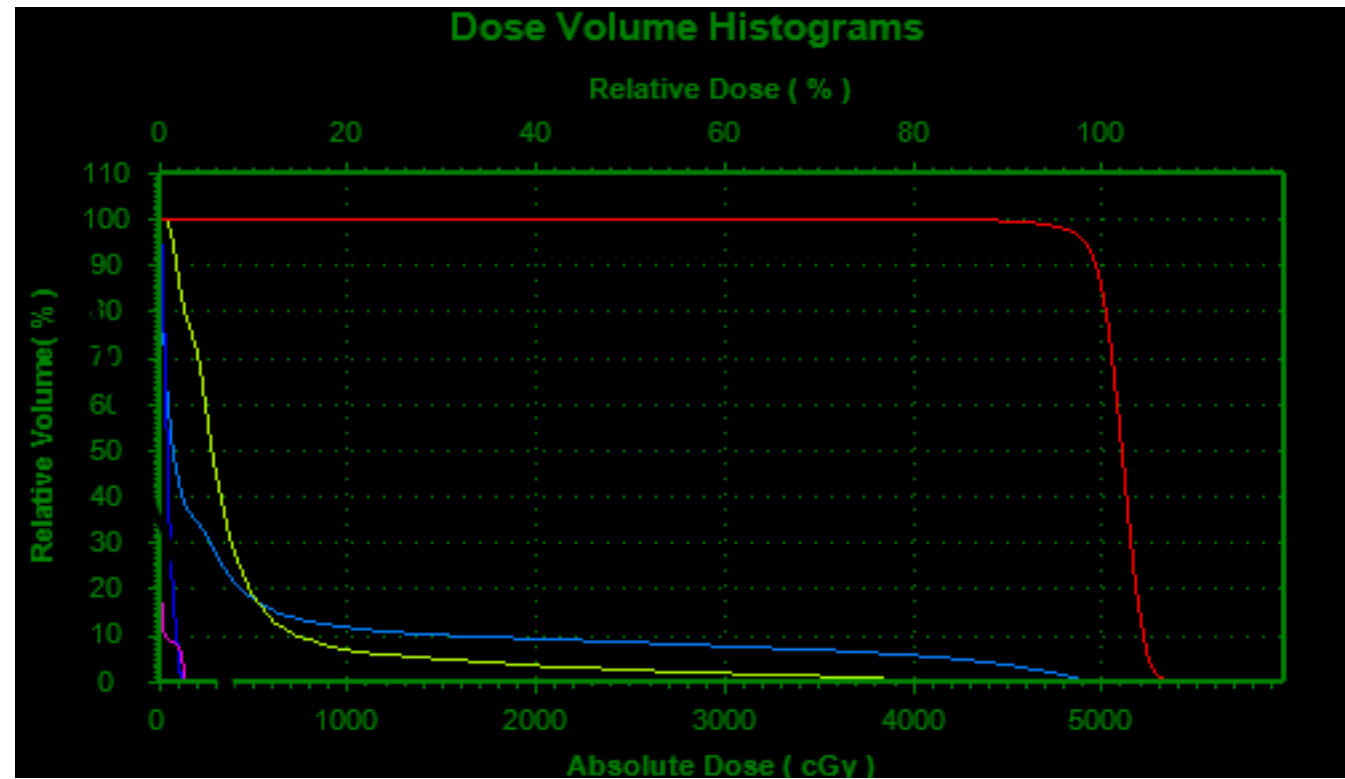

Şekil 2. DVH'e bir örnek (Koyu mavi: Tiroid bezi, Kırmızı:PTV) 
Tablo 1. Grup-1 ve Grup-2 hastalarının ortalama tiroid bezi dozu, PTV dozu, tiroid bezi hacmi ve yaşları

$\begin{array}{cccc}\text { Ortalama PTV Doz } & \text { Ortalama Tiroid Bezi } & \text { Tiroid Bezi Hacmi } & \text { Yaş } \\ \text { (Gy) } & \text { Dozu (Gy) } & \text { (cc) } & \text { (Yıl) }\end{array}$

\begin{tabular}{lllll}
\hline Grup 1 & $51.023 \pm 0.677$ & $19.320 \pm 4.894$ & $16.565 \pm 7.403$ & $49.485 \pm 10.619$ \\
Grup-2 & $51.042 \pm 1.715$ & $0.315 \pm 0.241$ & $16.825 \pm 7.492$ & $51.255 \pm 12.417$ \\
\hline
\end{tabular}

Grup-1 ve Grup-2 arasindaki ERR değerleri arasındaki farkın istatistiksel olarak anlamlı olduğu görülmüştür $(\mathrm{p}<0.05)$. Grup-1'de supraklaviküler bölge lenf nodları RT alanına dahil edildiği için tirod bezinin aldığı doz ve buna bağlı ERR değerleri Grup-2'ye göre daha yüksektir. Grup-1 için ortalama ERR değeri 4.551 iken Grup-2 için ortalama ERR değeri 0.059 'dur. Belirlenen yaş aralıklarında ERR değişimleri
Şekil 3'de ve her alt grubun standart sapmaları Şekil 4'de görülmektedir. Grup-1 ve Grup-2 için ERR değerleri yaş aralıklarına göre şöyledir: 29- 40 yaş aralığı için 9.656 ve 0.123 ; $41-50$ yaş aralığı için 4.373 ve 0.1068 ; 51- 60 yaş aralığı için 1.883 ve $0.040 ; 61-70$ yaş aralığı için 0.881 ve 0.0293 ; $71-80$ yaş aralığı için 0.0067 ve 0.0067 'dır.

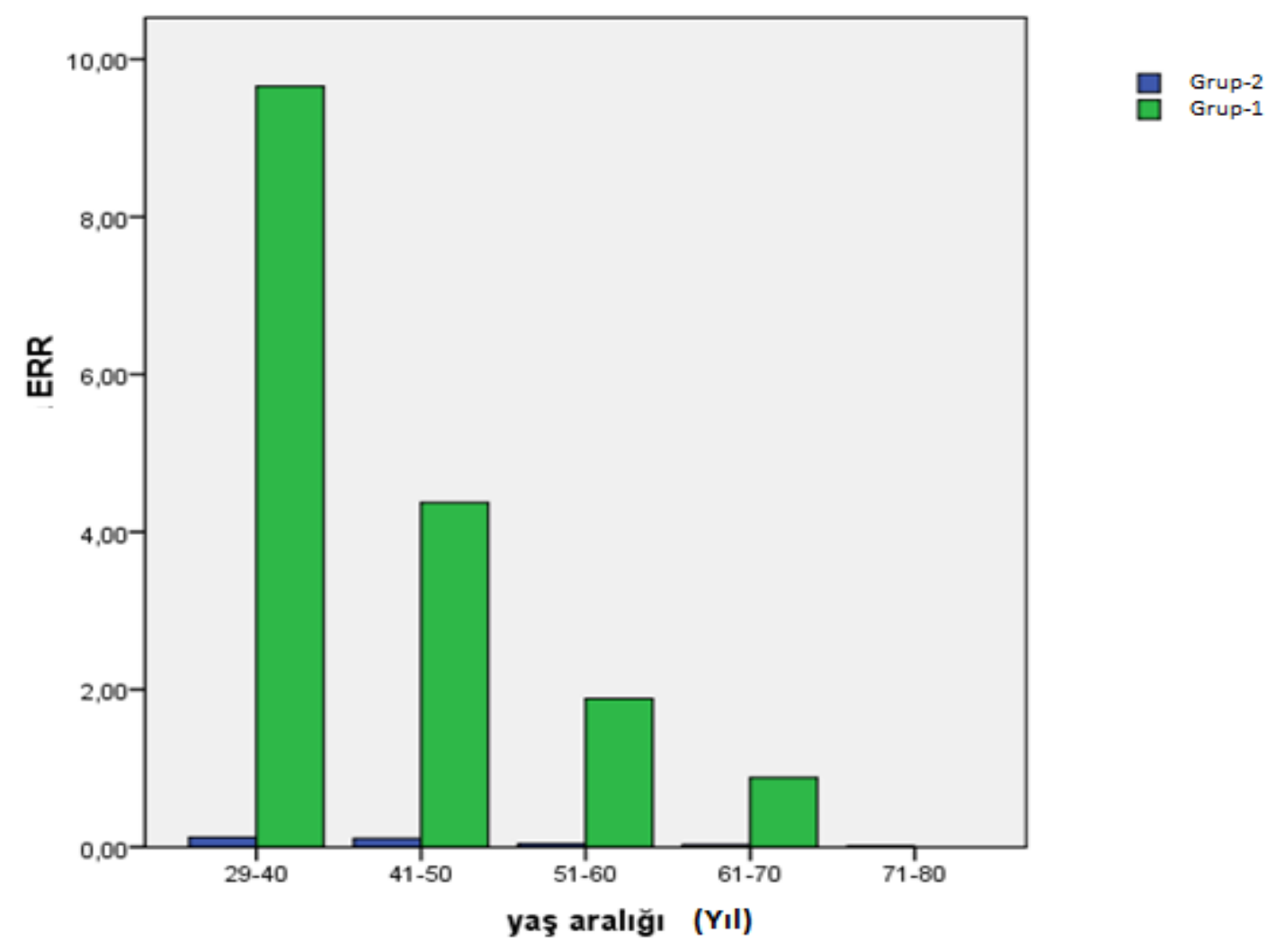

Şekil 3. Grup-1 ve Grup-2 için yaş aralığına bağlı ERR değerlerinin değişimi 


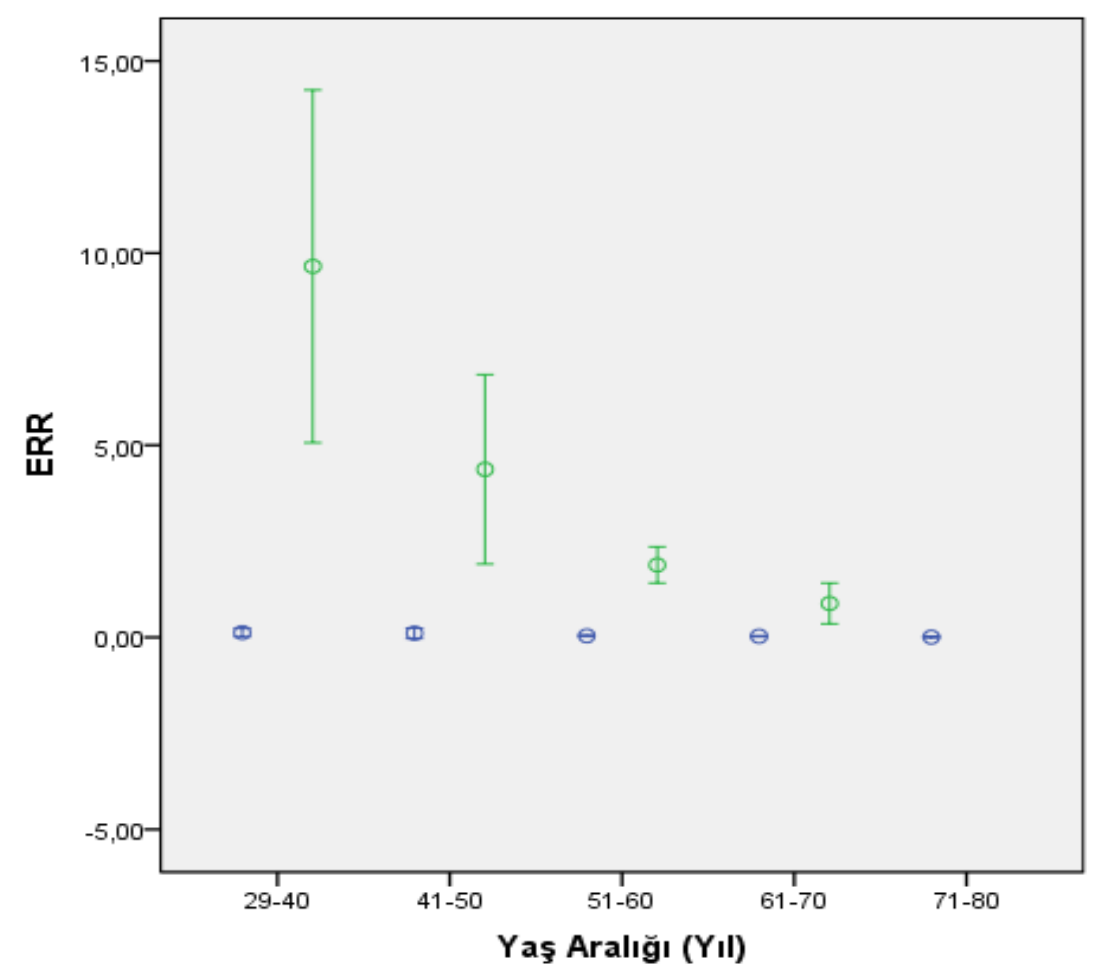

I Grup 2

I Grup 1

Şekil 4. Grup-1 ve Grup-2 için yaş aralığına bağlı ERR hata çubuğu grafiği

\section{Tartışma}

Meme RT'sinde PTV'nin verilen dozun tamamını alması istenirken, iyonize radyasyonun karsinojen etkisi göz önünde bulundurularak, karşı meme, akciğer, tiroid bezi gibi normal dokuların OaR dozlarının azaltılması gerekmektedir.11,12 Çünkü iyonize radyasyona maruz kalma, tiroid bezinde malignite gelişimine neden olabilecek risk faktörlerinden biridir. ${ }^{13} \mathrm{Bu}$ çalışmada, meme IMRT yapılan hastaların tiroid bezinde ikincil malignite gelişimi riski değerlendirilmiştir.

Çalışmada,

Grup-1'de supraklaviküler bölgenin ışınlama alanına dahil edilmesinden dolayı tiroid bezinin aldığı ortalama dozun, Grup-2'den oldukça yüksek olduğu görülmüștür. Buna bağlı olarak Grup-1 ve Grup-2, ERR değerleri arasındaki fark istatistiksel olarak anlamlıdır $(\mathrm{p}<0.05)$. Grup-1'de yaşa bağlı olarak hesaplanan ERR değerlerindeki eksponansiyel azalım belirgindir. Yani ışınlamanın yapıldığı yaş arttıkça, radyasyona bağlı tiroid bezinde malignite gelişme olasılığı azalmaktadır (Grafik 1). 2940 yaș aralığında ortalama ERR 9.656 iken
51-60 yaş aralığında 1.883 ve 71- 80 aralığında 0.067 'dir. Aynı şekilde standart sapma da yaşa bağlı azalma göstermektedir (Grafik 2). Grup-2'de ise ortalama ERR değeri oldukça düşük olmakla beraber, ERR ve standart sapma değişimleri yine yaşa bağlı olarak azalmaktadır. Fakat ERR değerleri, Grup-1 ile karşılaştırıldığında oldukça düşüktür. 29- 40 yaş aralığında ortalama ERR değeri 0.123, 51- 60 yaş aralığında 0.040 ve $71-80$ yaş aralığında 0.067'dir. Görüldüğü gibi tiroid bezinde ikincil malignite gelişme olasılıkları arasındaki fark, Grup-1 kadar belirgin değildir. Gruplar arasındaki tiroid bezi dozları farklı olmasına rağmen, yaș arttıkça iki gruptaki ERR değerleri birbirine yakınlaşmıştır. Yani ışınlama yapılan yaş arttıkça, alınan radyasyon dozundan dolayı tiroid bezinde malignite gelişme olasılığ azalmakta ve bu risk dozdan bağımsız hale gelmektedir. $\mathrm{Bu}$ nedenle tiroid bezinde ikincil malignite riski genç hastalardaki radyoterapi uygulamalarında önemli hale gelmektedir. ${ }^{14,15}$

Meme RT'si sonrası tiroid bezinde malignite gelişimi ile ilgili prospektif ve 
fantom çalıșmaları mevcuttur. Bazire ve ark. ${ }^{16}$, erken evre meme radyoterapisi sonrası ikincil malignite gelişimini takip ettikleri hastalarda, genel popülasyon ve RT almış kanser hastaları arasındaki insidans oranını 1.059 olarak bulmuşlardır $(17.7 / 16.7)$. Danovan ve ark.17, fantom kullanarak yaptıkları çalışmalarında tiroid bezinde ikincil malignite riski değerini \%0.1'den küçük olarak hesaplamışlar ve riskin ışınlama yaşı ile azaldığını göstermişlerdir. Wolny-Rokicka ve ark.18 yaptıkları prospektif çalışmada ise, meme IMRT'si uygulanan hastalarda iki yll sonra tiroid bezinde malignite oluşumunun artışı $\% 6^{\prime}$ dir.

Bizim çalışmamızda da, meme IMRT'si esnasında alınan radyasyonun, tiroid bezinde ikincil malignite gelişme riskini arttırdığı görülmüştür. Supraklaviküler bölgenin RT alanına dahil edildiği, genç hastalarda bu artış daha da belirgindir. $\mathrm{Bu}$ nedenle özellikle genç RT hastalarında ikincil malignite gelişimine yönelik sağlam ve geçerli risk değerlendirmesinin yapılması önerilmektedir.

\section{Kaynaklar}

1. Adam D, Suditu MB, Popa R, Ciocaltei V. Volumetric-modulated arc therapy vs. $3 \mathrm{~d}$ conformal radiotherapy for breast cancer. Romanian Reports in Physics. 2015; 67(3):978-986.

2. Erpolat OP, Akmansu M, Catlı Dinc S, Akkan $\mathrm{K}$, Bora $\mathrm{H}$. The evaluation of the feasibility of carotid sparing intensity modulated radiation therapy technique for comprehensive breast irradiation. Physica Medica 2017;36:60-65.

3. Muralidhar KR, Soubhagya B, Ahmed S. Intensity modulated radiotherapy versus volumetric modulated arc therapy in breast cancer: A comparative dosimetric analysis. Int J Cancer Ther Oncol 2015;3(2):1-6.

4. Lee B, Ahn SH, Kim H, Son J, Sung J, Han Y, Huh SJ, Kim JS, Kim DW, Yoon M. Radiotherapy-induced secondary cancer risk for breast cancer: 3D conformal therapy versus IMRT versus VMAT. J Radiol Prot 2014;34:325-331.
5. Abo-Madyan Y, Aziz MH, Aly MMOM, Schneider F, Sperk E, Clausen S, Giordano FA, Herskind C, Steil V, Wenz F, Glatting G. Second cancer risk after 3D-CRT, IMRT and VMAT for breast cancer. Radiother Oncol 2014; 110:471-6.

6. ICRP Recommendations of the International Commission on Radiological Protection (Users Edition). ICRP Publication 103 (Users Edition). Ann. ICRP 2007;37:2-4.

7. Committee to Assess Health Risks from Exposure to Low Levels of Ionizing Radiation, National Research Council. BEIR VII: Health Risks from Exposure to Low Levels of Ionizing Radiation: BEIR VII, Phase 2. Washington, National Academies Press, 2006.

8. United Nations Scientific Committee on the Effects of Atomic Radiation. Sources and Effects of Ionizing Radiation. New York, United Nation Publication, 2000.

9. Lee WC. Excess relative risk as an effect measure in case-control studies of rare diseases. PLoS ONE 2015;10(4):1-9.

10. Johansen S, Cozzi L, Olsen DR. A planning comparison of dose patterns in organs at risk and predicted risk for radiation induced malignancy in the contralateral breast following radiation therapy of primary breast using conventional, IMRT and volumetric modulated arc treatment techniques. Acta Oncol 2009;48(4):495-503.

11. Rooney KP, Miah AB, Bhide SA, Guerrero-Urbano MT, Sharabiani MT, Newbold KL, Grove L, Harrington KJ, Nutting $\mathrm{CM}$. Intensity modulated radiotherapy in locally advanced thyroid cancer: outcomes of a sequential phase I dose-escalation study. Radiother Oncol 2018; 127(1):43-48. 12. Johansen $S$, Danielsen $T$, Olsen DR. Estimated risk for secondary cancer in the contra-lateral breast following radiation therapy of breast cancer. Acta Oncologica 2008;47(3):391-396.

13. Schonfeld SJ, Lee CA. Berrington de Gonzalez A. Medical exposure to radiation and thyroid cancer. Clinical Oncology 2011;23:244-250.

14. Athar BS, Paganetti H. Comparison of second cancer risk due to out-of-field doses from 6-MV IMRT and proton therapy based on 6 pediatric patient treatment plans. Radiother Oncol. 2011;98(1):87-92. 
15. Xu XG, Bednarz B, Paganetti H. A review of dosimetry studies on external-beam radiation treatment with respect to second cancer. Phys. Med. Biol. 2008;53:193-241.

16. Bazire L, De Rycke Y, Asselain B, Fourguet A, Kirova YM. Risks of second malignancies after breast cancer treatment: Long-term results. Cancer/Radiothérapie 2017;21:10-15.

17. Donovan EM, James $\mathrm{H}$, Bonora $\mathrm{M}$, Yarnold JR, Evans PM. Second cancer incidence risk estimates using BEIR VII models for standard and complex external beam radiotherapy for early breast cancer. Med Phys. 2012;39(10):5814-5824.

18. Wolny-Rokicka E, Tukiendorf A, Wydmanski J, Roszkowska D, Staniul BS, Zembron-Lancy A. Thyroid function after postoperative radiation therapy in patients with breast cancer. Asian Pac J Cancer Prev. 2016;17(10):4577-4581. 